\title{
Age-Related Changes in Antioxidative Enzyme Capacity in Tongue of Fischer 344 Rats
}

\author{
Min-Kwan Baek $\cdot$ Kyung-Ok Kim² $\cdot$ Hyun-Jin Kwon² $\cdot$ Yong-Woo Kim¹ $\cdot$ Joo-Hyun Woo ${ }^{1} \cdot$ Dong-Young Kim ${ }^{1}$ \\ ${ }^{1}$ Department of Otolaryngology-Head and Neck Surgery and ${ }^{2}$ Medical Research Institute, Gachon University Gil Hospital, Incheon, Korea
}

\begin{abstract}
Objectives. Antioxidative enzyme efficiency changes in some organs with age. However, no study has been conducted on age-related antioxidant enzyme changes in tongue. In the present study, the authors investigated the activities of four antioxidative enzymes and their protein expressions in the tongues of young and old Fischer 344 rats.

Methods. Age-dependent changes in the enzyme activities of total superoxide dismutase (SOD), Mn-SOD, Cu/Zn-SOD, catalase (CAT), and glutathione peroxidase (GPx) were determined using chemical kits, and the protein expressions levels of these enzymes by Western blotting. The study was conducted using rats aged 7 months (the young group, $\mathrm{n}=8$ ) and 22 months (the old group, $\mathrm{n}=8$ ).

Results. Total SOD, Cu/Zn-SOD, and GPx activities in the tongues of old rats were lower than in young rats, and similarly, corresponding protein expressions were downregulated in old rats. On the other hand, although the protein expressions of Mn-SOD and CAT were lower in old rats, their enzyme activities were not.

Conclusion. The results of this study provide a possible mechanism for the tongue aging process, as in old Fischer 344 rats the antioxidant defense system was diminished with respect to enzyme activity levels and protein abundances.
\end{abstract}

Keywords. Antioxidants; Tongue; Aging; Oxidative Stress

\section{INTRODUCTION}

The free radical theory is one hypothesis associated with aging [1]. This theory proposes reactive oxygen species (ROS), such as, hydrogen peroxide and superoxide and hydroxyl radicals cause oxidative damage to many biological macromolecules $[2,3]$. Several reports have shown electron transport chain deficiency causes an increase in the production of ROS, but there is no uniformity of results as to how the antioxidant defense system is affected by age [4-6]. Reported results indicate increases or decreases, or even no change in antioxidant enzyme activities in various tissues as a result of aging [6-8]. Nevertheless, it is gen-

\footnotetext{
- Received October 25, 2015

Revised November 30, 2015

Accepted December 29, 2015

- Corresponding author: Dong-Young Kim

Department of Otolaryngology-Head and Neck Surgery, Gachon University

Gil Hospital, 21 Namdong-daero 774beon-gil, Namdong-gu, Incheon

21565, Korea

Tel: +82-32-460-3762, Fax: +82-32-467-9044

E-mail: hndyk@gilhospital.com
}

erally believed that the antioxidant defense is generally weakened by the aging process [8-10].

The antioxidant system plays a vital role in the cells of aerobic organisms by protecting them from oxidative stress. Superoxide dismutases (SODs), including mitochondrial Mn-SOD and cytosolic $\mathrm{Cu} / \mathrm{Zn}-\mathrm{SOD}$, convert $\mathrm{O}_{2}^{-}$to $\mathrm{H}_{2} \mathrm{O}_{2}$, which is then decomposed to water by catalase (CAT) and glutathione peroxidase (GPx). Accordingly, factors that diminish antioxidative enzyme activity tend to result in ROS accumulation [11]. In some circumstances, oxidative stress up-regulates antioxidative enzyme activity via various signaling pathways, whereas in aged animals, oxidative damage is usually associated with diminished antioxidant system capacity $[12,13]$.

Aging studies have been performed extensively on brain, heart, liver, kidney, skeletal muscle, peripheral blood cells, and urinary systems, but it has not been determined whether such findings apply equally to aged head and neck organs, such as the tongue. Strong evidence links the unfavorable accumulation of ROS and oxidative damage associated with aging and human diseases $[14,15]$. The tongue is much affected by age-related dis-

Copyright @ 2016 by Korean Society of Otorhinolaryngology-Head and Neck Surgery.

This is an open-access article distributed under the terms of the Creative Commons Attribution Non-Commercial License (http://creativecommons.org/licenses/by-nc/4.0)

which permits unrestricted non-commercial use, distribution, and reproduction in any medium, provided the original work is properly cited. 
eases of the head and neck area, such as mouth burning syndrome, tongue cancer, and glossitis [16-18]. We undertook this investigatory study to determine and compare antioxidant capacities by measuring the activity levels and protein expressions of four antioxidant enzymes in the tongue tissues of old and young Fischer 344 rats.

\section{MATERIALS AND METHODS}

\section{Experimental animals}

Fischer 344 rats of 7 months (the young group, $n=8$ ) and 22 months (the old group, $n=8$ ) were obtained from the Aging Tissue Bank of Busan National University, South Korea. Animals were anesthetized with carbon dioxide, and tongues were quickly removed and minced on ice to obtain homogenous samples. Tissues were frozen in liquid nitrogen and then stored at $-80^{\circ} \mathrm{C}$ until required. The Institutional Animal Care and Use Committee of the Gachon University Gil Medical Center of South Korea approved all animal procedures (LCDI-2015-0023).

\section{Antioxidative enzyme activity assays}

Antioxidative enzyme activities were determined using Cayman chemical kits (Cayman Chemical Co., Ann Arbor, MI, USA). Tissues from tongue of young and old rats were homogenized. Cell debris was pelleted and the resulting supernatants were used for the enzyme activity assays.

SOD activities were measured at $450 \mathrm{~nm}$ as the rate of suppression of reduction of tetrazolium salt when superoxide anion radical was generated during oxidation of xanthine by xanthine oxidase. The reaction mixture contained $50 \mathrm{mM}$ Tris- $\mathrm{HCl}, \mathrm{pH}$ 8.0, $0.1 \mathrm{mM}$ diethylenetriaminepentaacetic acid and $0.1 \mathrm{mM}$ hypoxanthine, tetrazolium salt, and xanthine oxidase. One unit of SOD activity was defined as the amount of enzyme needed to exhibit $50 \%$ dismutation of the superoxide radical. The SOD assay provided results for total SOD, Mn-SOD, and Cu/Zn-SOD.

GPx activity was measured at $340 \mathrm{~nm}$ indirectly by a coupled reaction with glutathione reductase (GR). Oxidized glutathione

\section{H I}

- Mn-superoxide dismutase (SOD), Cu/Zn-SOD, glutathione peroxidase (GPx), and catalase (CAT) protein expressions in the tongue of old rats were downregulated.

- Total SOD, Cu/Zn-SOD, and GPx activities in the tongue of old rats were lower than in young rats.

- The expression of Mn-SOD and CAT proteins were low in old rats, while their enzyme activities were not.

- Diminishing antioxidative enzyme activity levels and protein abundances provide a possible mechanism for the tongue aging process. (glutathione disulfide, GSSG), produced upon reduction of hydroperoxide by GPx, is recycled back to its reduced state by GR and nicotinamide adenine dinucleotide phosphate (NADPH), and the associated oxidation of NADPH to NADP ${ }^{+}$is accompanied by a decrease in absorbance at $340 \mathrm{~nm}$. When GPx activity is rate limiting, the rate of decrease of $A_{340}$ is directly proportional to sample GPx activity. One unit of GPx activity was defined as the amount of enzyme required to oxidize $1.0 \mathrm{nmol}$ of $\mathrm{NADPH}$ to $\mathrm{NADP}^{+}$per minute at $25^{\circ} \mathrm{C}$.

CAT activity was determined at $540 \mathrm{~nm}$ by reacting CAT with methanol in the presence of an optimal concentration of $\mathrm{H}_{2} \mathrm{O}_{2}$. The formaldehyde produced as by product was measured colorimetrically using 4-amino-3-hydrazino-5-mercapto-1,2,4-triazole (Purpald) as chromogen. One unit of CAT activity was defined as the amount of enzyme required to produce $1.0 \mathrm{nmol}$ of formaldehyde per minute at $25^{\circ} \mathrm{C}$.

\section{Western analysis}

Tongue homogenates $(10 \% \mathrm{w} / \mathrm{v})$ were prepared in lysis buffer, containing $20 \mathrm{mM}$ Tris-Cl pH 7.4, 1\% Triton X-100, $150 \mathrm{mM}$ $\mathrm{NaCl}, 2 \mathrm{mM}$ EGTA (ethylene glycol tetraacetic acid), and protease inhibitor (Roche Diagnostics GmbH, Penzberg, Germany) at $4^{\circ} \mathrm{C}$. Homogenates were centrifuged at $10,000 \mathrm{~g}$ for 10 minutes at $4^{\circ} \mathrm{C}$ to remove nuclear fragments and tissue debris. Total proteins $(20 \mu \mathrm{g})$ were resolved by $15 \%$ SDS-PAGE (sodium dodecyl sulfate-polyacrylamide gel, ProtoGel; National Diagnostics, Atlanta, GA, USA) and transferred to nitrocellulose membranes, which were blocked by incubating them in $5 \%$ nonfat dry milk in phosphate-buffered saline for 1 hour at room temperature. Membranes were then incubated with primary antibodies for Mn-SOD, Cu/Zn-SOD, GPx, CAT, and glyceraldehyde-3-phosphate dehydrogenase (GAPDH; Abcam, Cambridge, UK) overnight, washed three times with Tris-buffered saline containing $0.1 \%$ Tween 20 (TTBS), and further incubated for 30 minutes with horseradish peroxidase-conjugated antirabbit immunoglobulins $(1: 5,000)$. After washing with TTBS, blots were visualized using an enhanced chemiluminescence detection system (Bio-Rad, Hercules, CA, USA) according to the manufacturer's instructions.

\section{Statistical analysis}

The significances of differences were determined using MannWhitney test. Statistical significance was accepted for $P$-values $<0.05$ and the analysis was conducted using the PASW SPSS ver. 18.0 (SPSS Inc., Chicago, IL, USA).

\section{RESULTS}

\section{Antioxidative enzyme activities}

Significant reductions in the activities of total SOD, Cu/Zn-SOD, and GPx were found in the tongue tissues of old (22-month-old) 



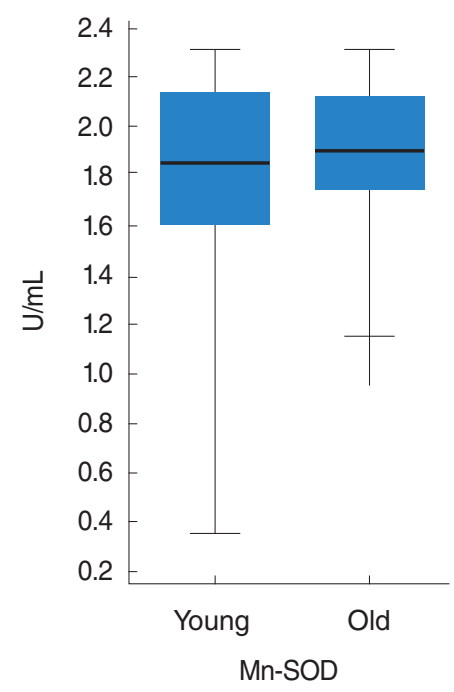

B
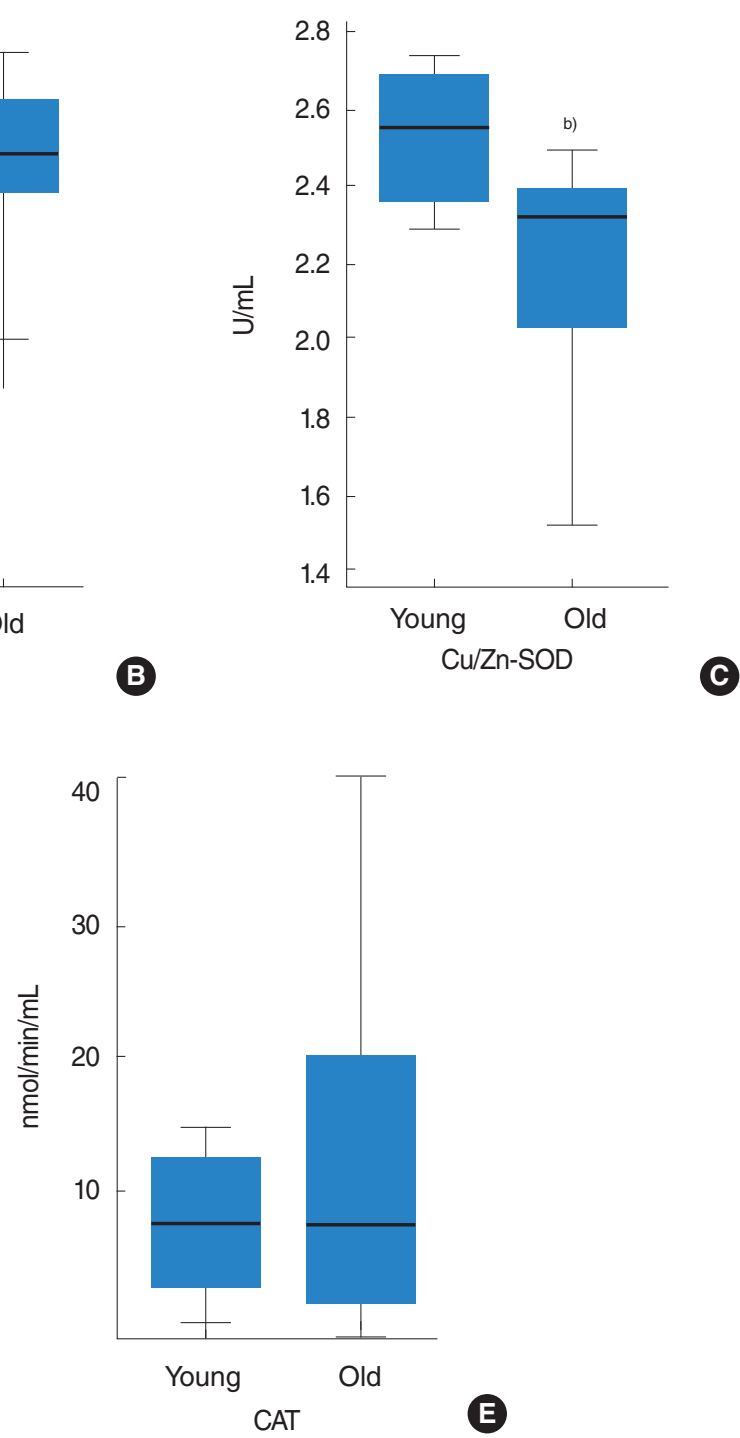

Fig. 1. (A) Total SOD, (B) Mn-SOD, (C) Cu/Zn-SOD, (D) GPx, and (E) CAT activities in the rats' tongues of two age groups, namely 7 months (young group, $n=8$ ) and 22 months (old group, $n=8$ ). One unit of SOD is defined as the amount of enzyme needed to catalyze the dismutation of the superoxide $\left(\mathrm{O}_{2}{ }^{-}\right)$radical by $50 \%$ at $25^{\circ} \mathrm{C}$. One unit of GPx was defined as the amount of enzyme required to cause the oxidation of 1.0 $\mathrm{nmol}$ of $\mathrm{NADPH}$ to $\mathrm{NADP}^{+}$per minute at $25^{\circ} \mathrm{C}$. One unit of CAT was defined as the amount of enzyme required to produce $1.0 \mathrm{nmol}$ of formaldehyde per minute at $25^{\circ} \mathrm{C}$. Results are expressed as median values. SOD, superoxide dismutase; GPx, glutathione peroxidase; CAT, catalase; NADP, nicotinamide adenine dinucleotide phosphate. ${ }^{a)} P<0.05$. ${ }^{\text {b) }} P<0.01$ vs. the young group by the Mann-Whitney test.

rats. However, Mn-SOD and CAT activities were not significantly different in the tongue tissues of young (7-month-old) and old rats. Total SOD activity was $13 \%$ lower in old rats (Fig. 1A). Cu/ Zn-SOD had much more activity than Mn-SOD in young and old rats (Fig. 1B, C). Cu/Zn-SOD activity was $11.5 \%$ lower in old rats (Fig. 1C), and absolute GPx enzyme activity in old rats was only approximately $25 \%$ of that in young rats (Fig. 1D).

\section{Antioxidative enzyme protein expression}

Antioxidant capacities were also evaluated by measuring protein expression levels. Western blotting showed the protein ex- pression levels of Mn-SOD, Cu/Zn-SOD, CAT, and GPx in tongue tissues. The density of each band was normalized to its corresponding GAPDH level from the same sample. The levels of $\mathrm{Mn}-\mathrm{SOD}$ and $\mathrm{Cu} / \mathrm{Zn}-\mathrm{SOD}$ protein are presented in Fig. $2 \mathrm{~A}$ and $2 \mathrm{~B}$. In the tongue, these proteins significantly decreased with age ( $P=0.015$ and $P=0.005)$. The levels of GPx and CAT protein expressed in the tongue of young and old rats are shown in Fig. 2C and 2D. The amount of GPx and CAT dramatically decreased with age, i.e., 2 times and 4 times, respectively $(P=0.021$ and $P=0.001)$. 

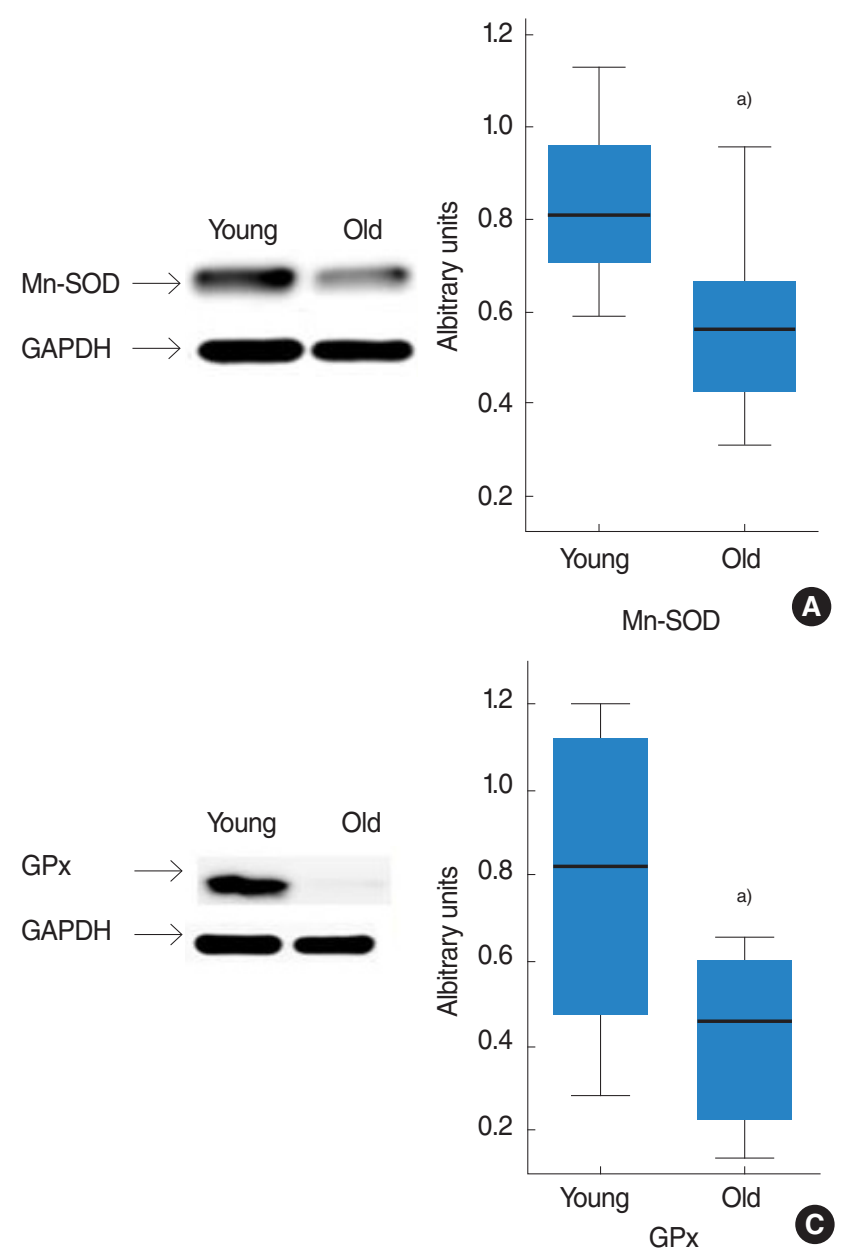
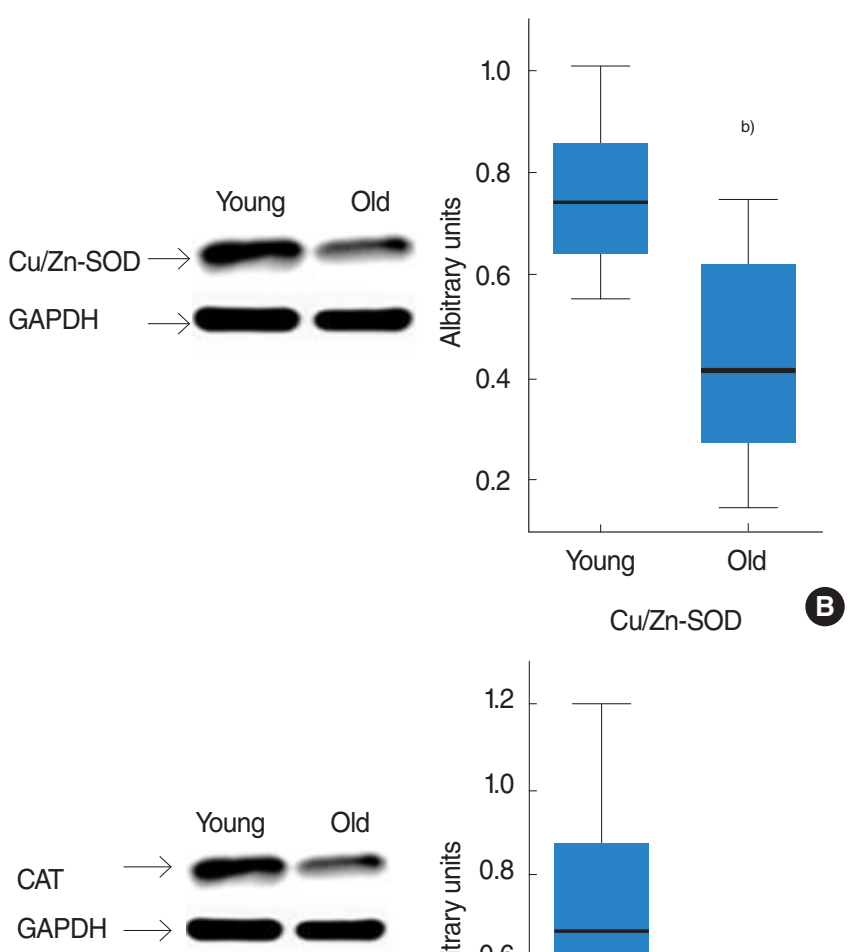

Fig. 2. Western blot analysis of antioxidant enzyme protein expressions in the rats' tongues of two age groups, namely 7 months (young group, $\mathrm{n}=8$ ) and 22 months (old group, $\mathrm{n}=8$ ). Protein (20 ug) lysates from tongue homogenates of young and old rats were resolved by SDS-PAGE (sodium dodecyl sulfate-polyacrylamide gel) and probed with Mn-SOD, Cu/Zn-SOD, CAT, and GPx antibodies as described in Materials and Methods. GAPDH was used as a loading control. Blots of (A) Mn-SOD, (B) Cu/Zn-SOD, (C) GPx, and (D) CAT were shown with quantification of the protein expression by normalizing each band signal to their corresponding GAPDH band. Results are expressed as median values. SOD, superoxide dismutase; GPx, glutathione peroxidase; CAT, catalase; GAPDH, glyceraldehyde-3-phosphate dehydrogenase. ${ }^{a} P<0.05$. b) $P<0.01$ vs. the young group by the Mann-Whitney test.

\section{DISCUSSION}

The effects of aging on free radical production and the antioxidant system have been widely investigated in major organs. However, age-related changes in the antioxidant system of the tongue have not been examined. In the present study, we examined and compared the activities and protein expressions of antioxidant enzymes (Mn-SOD, Cu/Zn-SOD, CAT, and GPx) in the tongue tissues of 7-month (young) and 22-month (old) rats.

The tapering of skeletal growth in male and female rats occurs at 7 months, while the closing of the last growth plates happens in humans at 20 years of age. Therefore this study defined a rat at 7 months to be similar to a human at 20 years of age. Furthermore, reproductive senescence in female rats occurs variably somewhere between 15 and 24 months of age (average 20 months). According to the American Medical Association, the average age of menopause in women is 51 years old. Therefore 22 months in the life of a rat is similar to a human between 55 and 60 years of age (adult phase: 11.8 rat days $=1$ human year) [19]. The author of this study defined a young rat at 7 months and an old rat at 22 months and compared each group.

Age-related changes in antioxidant enzymes are usually tissue dependent [20]. In a previous study, it was found that antioxidant defense capacity was lower in old than in young rats, but not in striated muscles. GPx activities were lower in old rats in all tissues examined, except muscles, and CAT activities were found to be lower in liver and kidneys. Although heart SOD activity was high in old rats, a general non-significant decrease in antioxidant defense was observed. No change was observed in GPx activity, while CAT and SOD activities were elevated in 
striated muscle of old rats [21].

In a previous study, total SOD activity was found to decrease with age in the kidneys, brains, and hearts of rats and mice, and to decrease markedly in senescence-accelerated mice [22]. In another study, CAT activity was found to show age-related decreases in mouse liver and kidney tissues, and higher SOD activity was observed in the cerebellums of aged rats [23]. However, in another study, SOD and CAT activities were similar old and young rats [24,25]. Hazelton and Lang [26] reported decreased GPx activity in kidneys was associated with aging. However, high levels of GPx activity have been reported in kidneys, hearts and testes of 19-month-old Sprague-Dawley rats and in the brains of 20-month-old Wistar rats [25]. Thus, it remains unclear how aging affects antioxidative enzyme activity.

Antioxidant enzymatic efficiency can be measured from the protein functional level, which is quantified in unit amounts of protein, or from the protein abundance level, although are not differentiated in most studies [27]. In the present study, we compared total SOD, Mn-SOD, Cu/Zn-SOD, GPx, and CAT activities in the tongue tissues of young and old rats, and we found total SOD, Cu/Zn-SOD, and GPx activities were significantly lower in old rats. Furthermore, Western blot results showed aging influenced the tongue significantly and that the protein expression levels of Mn-SOD, Cu/Zn-SOD, GPx, and CAT were lower in old rats. Thus, our protein level and enzyme activity results indicate reduced overall antioxidant ability in the tongues of older animals despite the observed lack of significant change in the enzyme activities of Mn-SOD and CAT.

After glutathione (GSH) levels have diminished significantly and oxidized glutathione (GSSG) levels have increased significantly in the heart tissues of aged rats, animals depend on increased CAT activity as a compensatory mechanism to decompose $\mathrm{H}_{2} \mathrm{O}_{2}$ to water [28]. As shown in Fig. 1E, CAT activity was non-significantly higher in old rats, probably because metabolically active tissues are sensitive to age-related GSH depletion and redox state perturbation. Vinokur et al. [29] reported that thioredoxin reductase (TrxR) significantly increased with age in the tongues of rats. TrxR catalyzes the oxidation of NADPH to $\mathrm{NADP}^{+}$in oxido-reduction cycle of methionine. GPx activity is defined as the amount of enzyme that will cause the oxidation of $1.0 \mathrm{nmol}$ of NADPH to NADP ${ }^{+}$[30]. In this study, GPx activity and expression significantly decreased in an aged tongue. The individuals may depend on the increased TrxR in aged rats' tongues to compensate for the decreased GPx to oxidize $\mathrm{NADPH}$ to $\mathrm{NADP}^{+}$. Our Western blot results show that the expressions of all four enzymes were down-regulated in tongue tissues, which are in-line with the lower enzymatic activities observed (excepting those of Mn-SOD and CAT). It should be noted that the findings of the present study are in general agreement with those of major organ studies $[23,26,31]$.

The present study suggests the mechanism underlying the aging process in the rat tongue is associated with general decreases in the efficacy of the antioxidant defense system at the enzyme activity and protein abundance levels. Further study is needed to confirm that these events will cause the unfavorable release and accumulation of ROS in the tongue, resulting in aging and whether this will provide clues in finding the cause of age-related tongue disease.

\section{CONFLICT OF INTEREST}

No potential conflict of interest relevant to this article was reported.

\section{ACKNOWLEDGMENTS}

The authors thank the Aging Tissue Bank at Busan National University for providing animal tissues. This work was supported financially by Gachon University Gil Medical Center Research Foundation, Incheon, Republic of Korea.

\section{REFERENCES}

1. Harman D. Aging: a theory based on free radical and radiation chemistry. J Gerontol. 1956 Jul;11(3):298-300.

2. Cutler RG. Human longevity and aging: possible role of reactive oxygen species. Ann NYAcad Sci. 1991 Jul;621:1-28.

3. Wong YT, Ruan R, Tay FE. Relationship between levels of oxidative DNA damage, lipid peroxidation and mitochondrial membrane potential in young and old F344 rats. Free Radic Res. 2006 Apr;40(4): 393-402.

4. Feuers RJ,Weindruch R, Hart RW. Caloric restriction, aging, and antioxidant enzymes. Mutat Res. 1993 Dec;295(4-6):191-200.

5. Fannin SW, Lesnefsky EJ, Slabe TJ, Hassan MO, Hoppel CL. Aging selectively decreases oxidative capacity in rat heart interfibrillar mitochondria. Arch Biochem Biophys. 1999 Dec;372(2):399-407.

6. Jung K, Henke W. Developmental changes of antioxidant enzymes in kidney and liver from rats. Free Radic Biol Med. 1996;20(4):6137.

7. Dogru-Abbasoglu S, Tamer-Toptani S, Ugurnal B, Kocak-Toker N, Aykac-Toker G, Uysal M. Lipid peroxidation and antioxidant enzymes in livers and brains of aged rats. Mech Ageing Dev. 1997 Nov;98(2):177-80.

8. Gomi F, Matsuo M. Effects of aging and food restriction on the antioxidant enzyme activity of rat livers. J Gerontol A Biol Sci Med Sci. 1998 May;53(3):B161-7.

9. De AK, Darad R.Age-associated changes in antioxidants and antioxidative enzymes in rats. Mech Ageing Dev. 1991 Jun;59(1-2):123-8.

10. Rikans LE, Hornbrook KR. Lipid peroxidation, antioxidant protection and aging. Biochim Biophys Acta. 1997 Dec;1362(2-3):116-27.

11. Ceballos-Picot I, Nicole A, Clement M, Bourre JM, Sinet PM. Agerelated changes in antioxidant enzymes and lipid peroxidation in brains of control and transgenic mice overexpressing copper-zinc superoxide dismutase. Mutat Res. 1992 Sep;275(3-6):281-93.

12. Vina J, Borras C, Gomez-Cabrera MC, Orr WC. Part of the series: from dietary antioxidants to regulators in cellular signalling and gene expression: role of reactive oxygen species and (phyto)oestro- 
gens in the modulation of adaptive response to stress. Free Radic Res. 2006 Feb;40(2):111-9.

13. Wei YH, Lee HC. Oxidative stress, mitochondrial DNA mutation, and impairment of antioxidant enzymes in aging. Exp Biol Med (Maywood). 2002 Oct;227(9):671-82.

14. Dröge W. Free radicals in the physiological control of cell function. Physiol Rev. 2002 Jan;82(1):47-95.

15. Galli F, Piroddi M, Annetti C, Aisa C, Floridi E, Floridi A. Oxidative stress and reactive oxygen species. Contrib Nephrol. 2005;149:24060 .

16. Perno M. Burning mouth syndrome. J Dent Hyg. 2001 Summer;75 (3):245-52.

17. Soudry E, Preis M, Hod R, Hamzany Y, Hadar T, Bahar G, et al. Squamous cell carcinoma of the oral tongue in patients over 75 years old. Aging Clin Exp Res. 2011 Jun;23(3):231-5.

18. Pinzon Tofino ME, Gaitan Cepeda LA. Aging and the oral cavity. Pract Odontol. 1989 Mar;10(3):33-6.

19. Quinn R. Comparing rat's to human's age: how old is my rat in people years? Nutrition. 2005 Jun;21(6):775-7.

20. Sohal RS, Arnold LA, Sohal BH. Age-related changes in antioxidant enzymes and prooxidant generation in tissues of the rat with special reference to parameters in two insect species. Free Radic Biol Med. 1990;9(6):495-500.

21. Gunduz F, Senturk UK, Kuru O, Aktekin B, Aktekin MR. The effect of one year's swimming exercise on oxidant stress and antioxidant capacity in aged rats. Physiol Res. 2004;53(2):171-6.

22. Boldyrev AA, Yuneva MO, Sorokina EV, Kramarenko GG, Fedorova TN, Konovalova GG, et al. Antioxidant systems in tissues of senescence accelerated mice. Biochemistry (Mosc). 2001 Oct;66(10): 1157-63.
23. Baird MB, Samis HV Jr. Regulation of catalase activity in mice of different ages. Gerontologia. 1971;17(2):105-15.

24. Siqueira IR, Fochesatto C, de Andrade A, Santos M, Hagen M, BelloKlein A, et al. Total antioxidant capacity is impaired in different structures from aged rat brain. Int J Dev Neurosci. 2005 Dec;23(8): 663-71.

25. Ehrenbrink G, Hakenhaar FS, Salomon TB, Petrucci AP, Sandri MR, Benfato MS. Antioxidant enzymes activities and protein damage in rat brain of both sexes. Exp Gerontol. 2006 Apr;41(4):368-71.

26. Hazelton GA, Lang CA. Glutathione peroxidase and reductase activities in the aging mouse. Mech Ageing Dev. 1985 Jan;29(1):71-81.

27. Nilakantan V, Zhou X, Hilton G, Roza AM, Adams MB, Johnson CP, et al. Hierarchical change in antioxidant enzyme gene expression and activity in acute cardiac rejection: role of inducible nitric oxide synthase. Mol Cell Biochem. 2005 Feb;270(1-2):39-47.

28. Kumaran S, Savitha S, Anusuya Devi M, Panneerselvam C. L-carnitine and DL-alpha-lipoic acid reverse the age-related deficit in glutathione redox state in skeletal muscle and heart tissues. Mech Ageing Dev. 2004 Jul;125(7):507-12.

29. Vinokur V, Grinberg L, Berenshtein E, Gross M, Moskovitz J, Reznick AZ, et al. Methionine-centered redox cycle in organs of the aero-digestive tract of young and old rats. Biogerontology. 2009 Feb;10(1):43-52.

30. Paglia DE, ValentineWN. Studies on the quantitative and qualitative characterization of erythrocyte glutathione peroxidase. J Lab Clin Med. 1967 Jul;70(1):158-69.

31. Rao G, Xia E, Richardson A. Effect of age on the expression of antioxidant enzymes in male Fischer F344 rats. Mech Ageing Dev. 1990 Mar;53(1):49-60. 